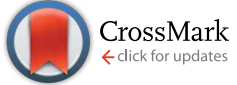

Cite this: RSC Adv., 2017, 7, 11929

Received 1st December 2016 Accepted 3rd February 2017

DOI: 10.1039/c6ra27610e

rsc.li/rsc-advances

\section{Investigation into 1,3-butadiene and other bulk chemicals' formation from bioethanol over Mg-Al catalysts $\uparrow$}

\author{
Meixiang Gao, ${ }^{\text {ab }}$ Minhua Zhang ${ }^{\mathrm{ab}}$ and Yonghui $\mathrm{Li}^{\star \mathrm{ab}}$
}

$\mathrm{Mg}$-Al catalysts were adopted in the direct synthesis of 1,3-butadiene and other bulk chemicals from bioethanol. The influence of $\mathrm{MgO}$ content and sample calcination temperature on the catalytic performance was investigated. The optimization of reaction conditions for 1,3-butadiene, ethylene and 1-butanol, including reaction temperatures and the feed rate of ethanol, was also carried out. The catalysts were characterized by $\mathrm{X}$-ray diffraction, nitrogen sorption, SEM, $\mathrm{NH}_{3}-\mathrm{TPD}, \mathrm{CO}_{2}-\mathrm{TPD}$ and FTIR of adsorbed pyridine. On the basis of these analysis results and catalytic performance of yielding 1,3-butadiene, both the $\mathrm{MgO}$ content and the calcination temperature play a great role on the nature of acid and basic sites, then the proper active sites for producing 1,3-butadiene and other important chemicals such as ethylene and 1-butanol have been elaborated. The balance of moderate acid-basic sites is crucial to production of 1,3-butadiene from ethanol. Ethylene is obtained on strong acid and strong basic sites. 1-Butanol tends to form on the strong basic sites. To further improve the target product selectivity, modifiers adjusting the balance of acidity-basicity need to be involved in the $\mathrm{Mg}-$ Al catalysts.

\section{Introduction}

In the $21^{\text {st }}$ century, the world is faced with the pressure of energy sources and energy-saving emission reduction. ${ }^{1}$ Utilization of reproducible resources effectively such as biomass, solar and geothermal power will be an effective measure to take to address those energy issue. Especially, large-scale utilization of the biomass is becoming a more and more important research topic. ${ }^{2}$ One of the most abundant practicable and sustainable raw materials produced from biomass is bioethanol, ${ }^{3-6}$ especially lots of researches have shifted toward non-grain biomass feedstock conversion to bioethanol recently. ${ }^{7-9}$ Conversion of bioethanol to some bulk chemicals is very important for several reasons, and maybe most significant of all, it helps to realize the reduction in nonrenewable fuel consumption and reduce environment pollution. ${ }^{10}$

1,3-Butadiene (BD) is widely applied in synthesis of rubber and polymers. ${ }^{11,12}$ With the development of economy, demand for BD is growing. The use of ethylene as raw material for

${ }^{a}$ Key Laboratory for Green Chemical Technology of Ministry of Education, R\&D Center for Petrochemical Technology, Tianjin University, Tianjin 300072, PR China. E-mail: yhli@tju.edu.cn; liyh@tju.edu.cn; Fax: +86-22-27401826; Tel: +86-22-27401826

${ }^{b}$ Collaborative Innovation Center of Chemical Science and Engineering, Tianjin 300072, China

$\dagger$ Electronic supplementary information (ESI) available. See DOI: $10.1039 / \mathrm{c} 6 \mathrm{ra} 27610 \mathrm{e}$

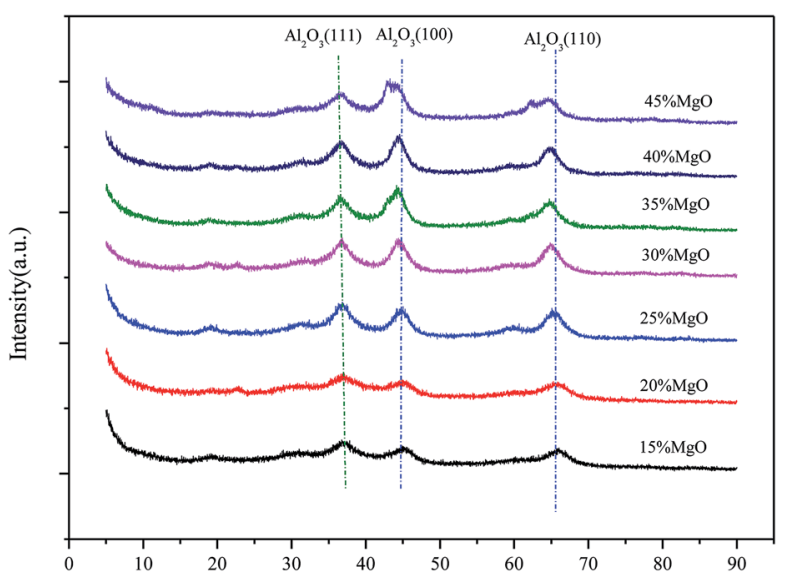

Fig. 1 XRD patterns of $\mathrm{Mg}-\mathrm{Al}$ catalysts with different $\mathrm{MgO}$ contents.

Table 1 Structural properties of $\mathrm{Mg}-\mathrm{Al}$ catalysts with different $\mathrm{MgO}$ contents

\begin{tabular}{lll}
\hline MgO content & $\begin{array}{l}\text { BET surface } \\
\text { area }\left(\mathrm{m}^{2} \mathrm{~g}^{-1}\right)\end{array}$ & $\begin{array}{l}\text { Average pore } \\
\text { diameter }(\AA)\end{array}$ \\
\hline $15 \%$ & 271.2 & 54 \\
$20 \%$ & 188.7 & 44 \\
$25 \%$ & 176.7 & 51 \\
$30 \%$ & 164.6 & 45 \\
$35 \%$ & 155.8 & 43 \\
$40 \%$ & 151.3 & 46 \\
$45 \%$ & 133.2 & 47
\end{tabular}



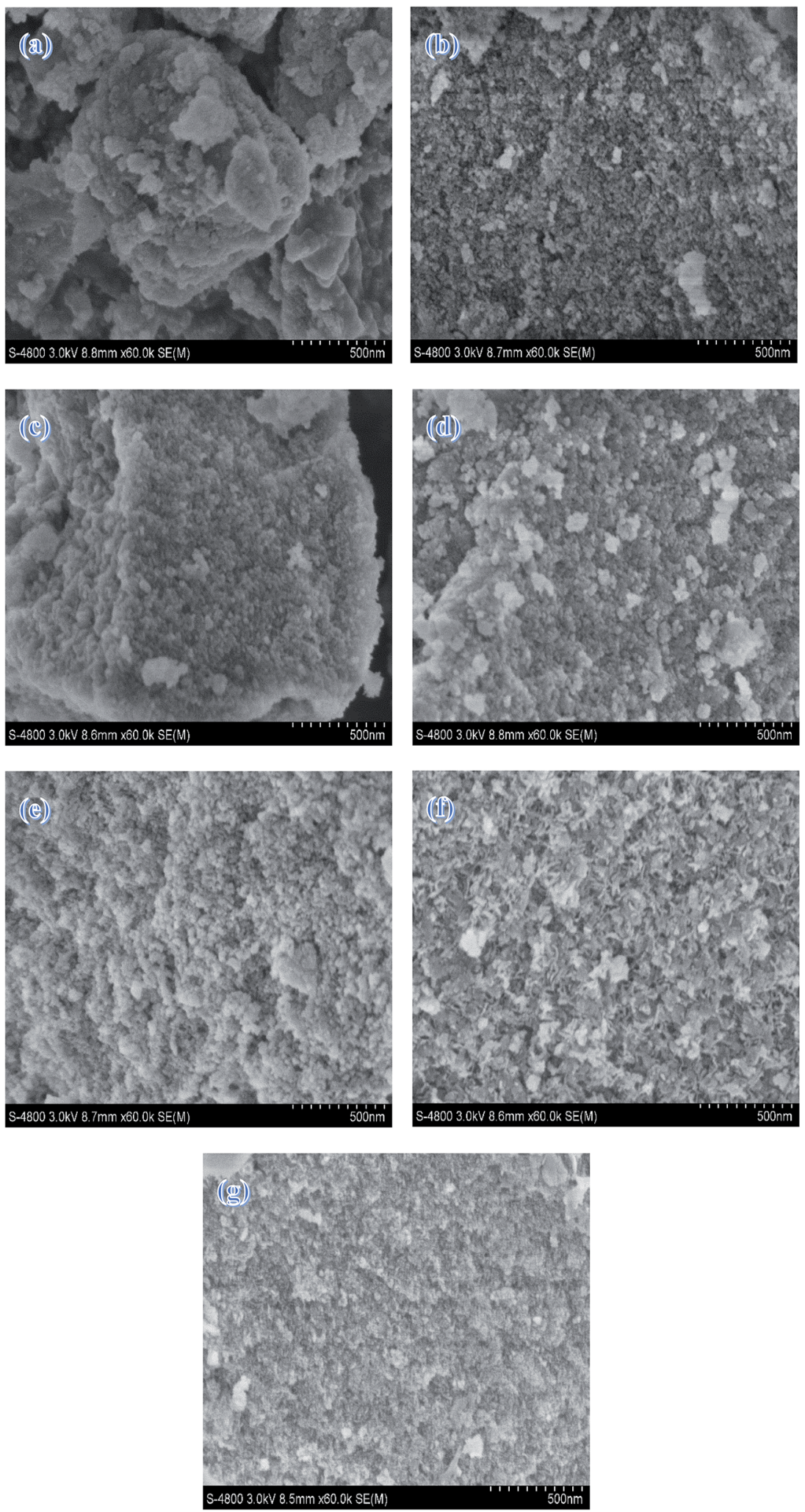

Fig. 2 SEM images of (a) $15 \% \mathrm{Mg}-\mathrm{Al}$ (b) $20 \% \mathrm{Mg}-\mathrm{Al}$ (c) $25 \% \mathrm{Mg}-\mathrm{Al}$ (d) $30 \% \mathrm{Mg}-\mathrm{Al}$ (e) $35 \% \mathrm{Mg}-\mathrm{Al}$ (f) $40 \% \mathrm{Mg}-\mathrm{Al}$ (g) $245 \% \mathrm{Mg}-\mathrm{Al}$.

chemical products is also being considered as an effective measure to offer the market an alternative of commodity plastics with a wide range of applications, especially to produce polyethylene and other polymers. ${ }^{13-16}$ Compared to the more commonly used ethanol, 1-butanol might be a promising gasoline replacement due to many advantages. Specifically, 1butanol has a higher energy density than ethanol and is less corrosive. ${ }^{17}$ 
The mechanism of ethanol conversion to $\mathrm{BD}$ is also open to debate, currently. But the following reaction route is approved by most scholars: acetaldehyde formation from ethanol, acetaldehyde coupling to acetaldol, dehydration of acetaldol to crotonaldehyde, reaction between ethanol and crotonaldehyde to crotyl alcohol and dehydration of crotyl alcohol to BD. The process of 1-butanol from ethanol follows a similar reaction route with that of conversion of ethanol to $\mathrm{BD}$, except that the final step to be the hydrogenation of the acetaldol to 1-butanol. Ethylene is formed from ethanol dehydration.

The main challenge in $\mathrm{BD}$ and other bulk chemicals production from ethanol is the relationship between product distribution and catalyst nature, although many classes of catalysts studied in this process. ${ }^{18-24}$ Our previous work was dedicated to improve new catalyst system and $\mathrm{Mg}-\mathrm{Al}$ catalysts were adopted in this process based on some literatures..$^{25-29}$ So the investigations on the influence of $\mathrm{MgO}$ content and calcination temperature on structure and properties of the catalysts, BD selectivity, and the optimization of reaction conditions will be focused in this study.

\section{Experimental}

\subsection{Catalyst preparation}

A balanced amount of $25 \%$ ammonia solution was slowly added in the mixed $\mathrm{Mg}\left(\mathrm{NO}_{3}\right)_{2} \cdot 6 \mathrm{H}_{2} \mathrm{O}$ and $\mathrm{Al}\left(\mathrm{NO}_{3}\right)_{3} \cdot 9 \mathrm{H}_{2} \mathrm{O}$ aqueous solutions respectively containing the $15 \mathrm{wt} \%, 20 \mathrm{wt} \%, 25 \mathrm{wt} \%$, $30 \mathrm{wt} \%, 35 \mathrm{wt} \%, 40 \mathrm{wt} \%$ and $45 \% \mathrm{MgO}$ at $333 \mathrm{~K}$ under stirring, maintaining the $\mathrm{pH} 9-10$. Repeat the above operation until precipitate completely. All the precipitate samples were washed several times until the $\mathrm{pH}$ of the solution was 7 . Then these samples were dried at $353 \mathrm{~K}$ for $6 \mathrm{~h}$ and calcined at $773 \mathrm{~K}$ for $5 \mathrm{~h}$. The same method was adopted in the synthesis of $35 \mathrm{wt} \% \mathrm{Mg}-$ Al but the samples were respectively calcined at $723 \mathrm{~K}, 773 \mathrm{~K}$, $823 \mathrm{~K}, 873 \mathrm{~K}, 923 \mathrm{~K}$ and $973 \mathrm{~K}$.

\subsection{Catalyst characterization}

X-ray powdered diffraction patterns were obtained with a Rigaku Multiplex instrument using $\mathrm{Cu}-\mathrm{K}$ radiation operated at $40 \mathrm{kV}$ and $40 \mathrm{~mA}$. Nitrogen adsorption isotherms were determined at $77 \mathrm{~K}$ on a Micromeritics Tristar 3000 volumetric adsorption analyzer. Before the adsorption measurements, all samples were preprocessed at $673 \mathrm{~K}$ in a degassing station for $12 \mathrm{~h}$. Scanning electron micrograph (SEM) images were recorded on a Philips XL-30S FEG scanning electron microscope. The nature of acid sites and basic sites were measured by $\mathrm{NH}_{3}$-TPD and $\mathrm{CO}_{2}$-TPD using a Micromeritic Autochem II 2920. Pyridine adsorbed FTIR was studied on Thermo Scientific Nicolet 560 FTIR spectrometer with 64 scans at $4 \mathrm{~cm}^{-1}$ resolution.

\subsection{Catalytic test}

The reaction of ethanol conversion to $\mathrm{BD}$ and other bulk chemicals was performed in a fixed bed reactor system at atmospheric pressure. The $3.0 \mathrm{~g}$ catalyst sieved to $0.425-0.850$ $\mathrm{mm}$ (20-40 mesh) particle size was packed in the middle of the quartz tube $(R=22 \mathrm{~mm})$. Before the reaction, the catalyst was pretreated to the reaction temperature $(673 \mathrm{~K}$, heating rate $=5.0$ $\mathrm{K} \mathrm{min}^{-1}$ ) carried by $40 \mathrm{ml} \mathrm{min}^{-1} \mathrm{~N}_{2}$ flow. The reaction was then performed with a preset weight hourly space velocity (WHSV) at preset reaction temperature. Products were detected online by Agilent 7890A equipped with a Carbon-Plot column $(0.535 \mathrm{~mm}$ id $\times 3 \mu \mathrm{m}$ thickness $\times 30 \mathrm{~m}$ length) and Thermal Conductivity Detector (TCD). The optimization reaction conditions included reaction temperature of $623 \mathrm{~K}, 648 \mathrm{~K}, 673 \mathrm{~K}, 698 \mathrm{~K}$ and $723 \mathrm{~K}$ as well as WHSV of $0.8 \mathrm{~h}^{-1}, 1.2 \mathrm{~h}^{-1}, 1.4 \mathrm{~h}^{-1}, 1.8 \mathrm{~h}^{-1}, 2.2 \mathrm{~h}^{-1}$ and $2.4 \mathrm{~h}^{-1}$.

\section{Results and discussion}

\subsection{Properties of $\mathbf{M g}-\mathbf{A l}$ catalysts}

The structures of the $\mathrm{Mg}-\mathrm{Al}$ catalysts with different $\mathrm{MgO}$ contents were analyzed by powder X-ray diffraction (Fig. 1). The XRD patterns of the $\mathrm{Mg}-\mathrm{Al}$ samples with $15 \sim 40 \%$ show typical peaks in $2 \theta=37^{\circ}, 45^{\circ}$ and $65^{\circ}$, which corresponds to $\mathrm{Al}_{2} \mathrm{O}_{3}$

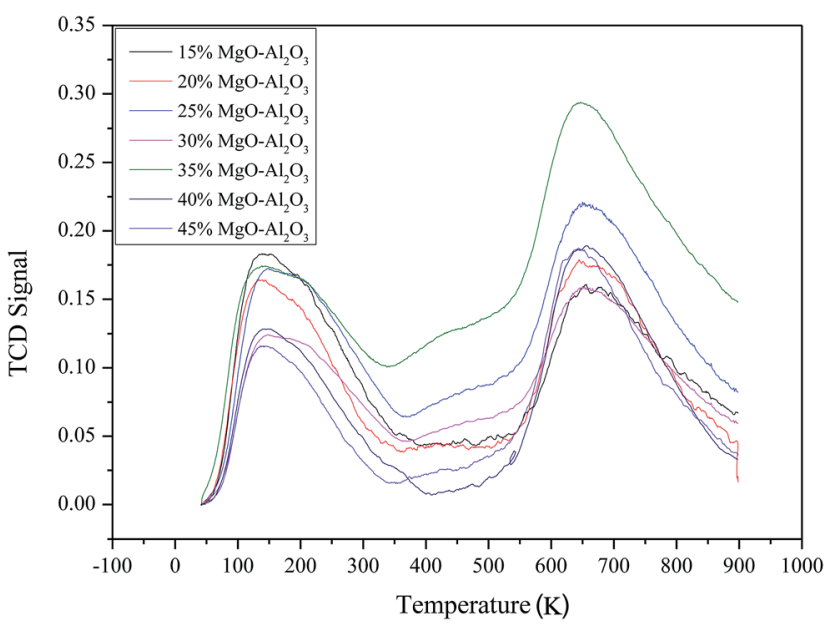

Fig. $3 \mathrm{NH}_{3}$-TPD on $\mathrm{Mg}-\mathrm{Al}$ catalysts with different $\mathrm{MgO}$ content.

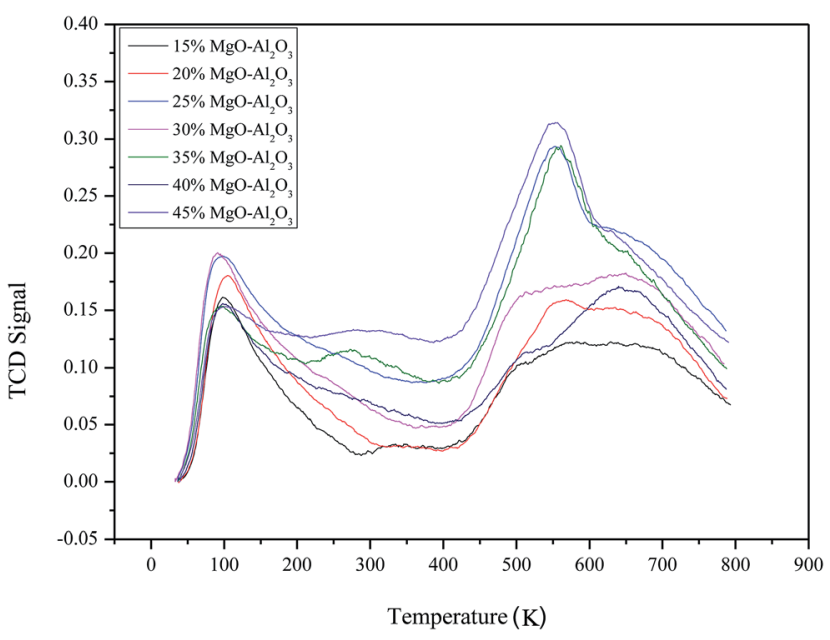

Fig. $4 \mathrm{CO}_{2}$-TPD on $\mathrm{Mg}-\mathrm{Al}$ catalysts with different $\mathrm{MgO}$ content. 
diffraction by planes (111), (100) and (110), respectively. While the $\mathrm{MgO}$ content increases to $45 \%$, the typical diffraction patterns of $\mathrm{MgO}$ gradually appears.
The textural characteristics of $\mathrm{Mg}-\mathrm{Al}$ catalysts with different $\mathrm{MgO}$ contents are presented in Table 1 . The BET surface areas gradually decreases as the $\mathrm{MgO}$ content increases from $15 \%$ to

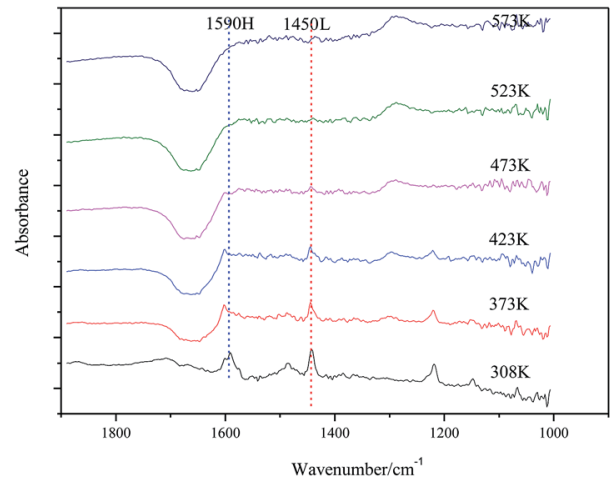

(a)

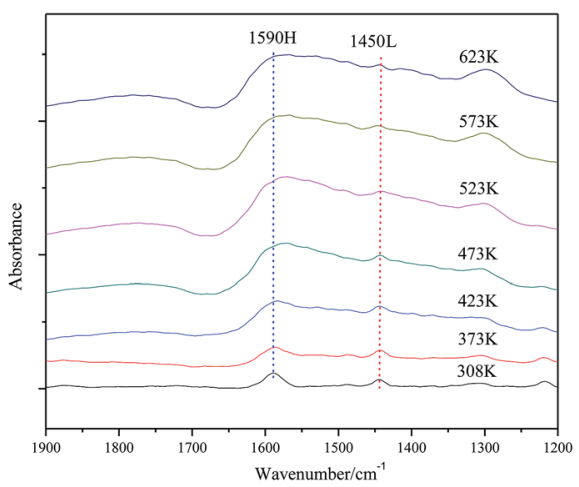

(c)

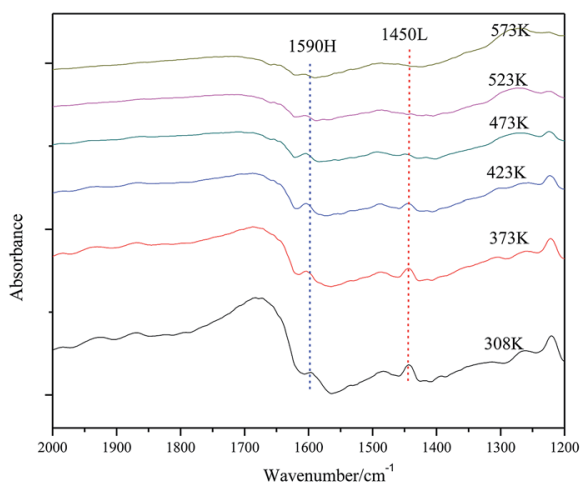

(e)

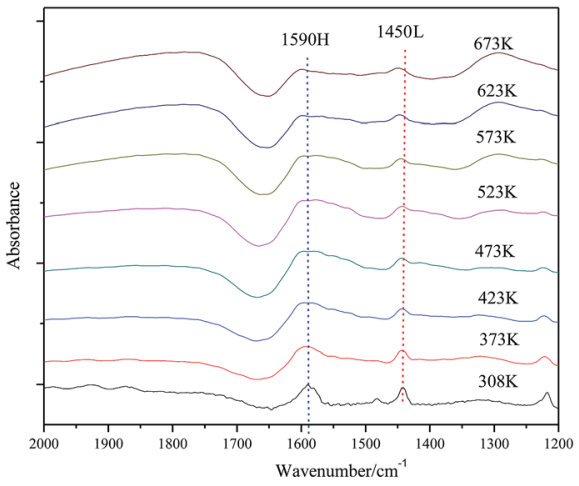

(b)

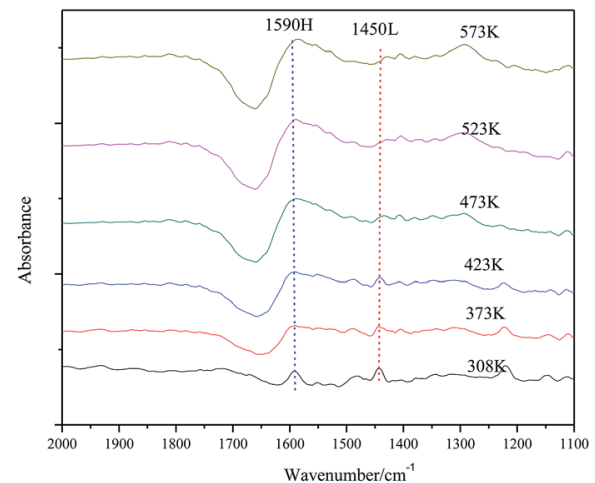

(d)

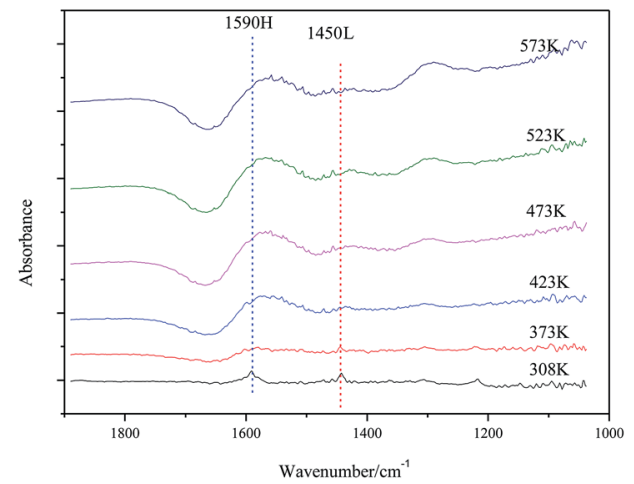

(f)

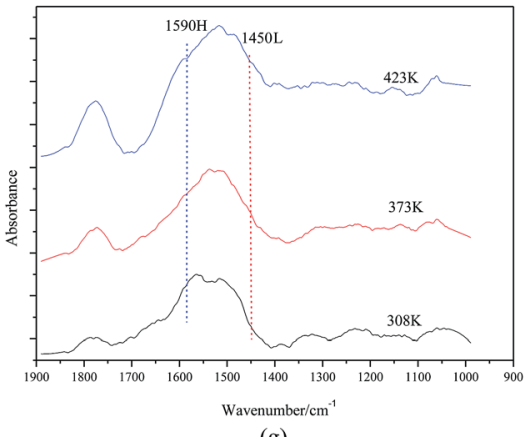

Fig. 5 FTIR spectra of (a) $15 \% \mathrm{Mg}-\mathrm{Al}$ (b) $20 \% \mathrm{Mg}-\mathrm{Al}$ (c) $25 \% \mathrm{Mg}-\mathrm{Al}$ (d) $30 \% \mathrm{Mg}-\mathrm{Al}$ (e) $35 \% \mathrm{Mg}-\mathrm{Al}$ (f) $40 \% \mathrm{Mg}-\mathrm{Al}$ (g) $45 \% \mathrm{Mg}-\mathrm{Al} \mathrm{after} \mathrm{pyridine}$ adsorption. 
$45 \%$. However, the change of the average pore diameters of all Mg-Al samples, which fluctuate in the range of 40-50 , shows no pattern with the increase of the $\mathrm{MgO}$ content, from $15 \%$ to $45 \%$.

SEM images of the Mg-Al samples with different $\mathrm{MgO}$ contents are shown in Fig. 2. As a whole, all the samples present irregularly blocky shapes. But as the MgO content increases, it exhibits a more spongy but distribution-intensive morphology. This may be explained by the fact that catalyst morphology shows $\mathrm{MgO}$ image when the $\mathrm{MgO}$ content increases to a certain extent. Moreover, this is agreed with the trends of the BET surfaces.

Acidic properties of $\mathrm{Mg}-\mathrm{Al}$ catalysts with different $\mathrm{MgO}$ contents were studied by $\mathrm{NH}_{3}$-TPD (Fig. 3). $\mathrm{NH}_{3}$-TPD profiles of all samples show two intensive peaks on $\sim 423 \mathrm{~K}$ and $\sim 923 \mathrm{~K}$, which suggests catalysts have weak and strong acid sites. The relative acid amounts of the catalyst estimated from the peak areas don't have much regulation as the $\mathrm{MgO}$ content increases. But the Mg-Al sample with 35\% MgO content has the most amount of acid sites on the surface.

Similarly, the basic properties of the catalysts were investigated by $\mathrm{CO}_{2}$-TPD and the results are presented in Fig. 4 . Two peaks of all samples appear at $\sim 373 \mathrm{~K}$ and $\sim 823 \mathrm{~K}$, respectively. The peak at low temperature corresponds to weak basic sites and the high temperature peak is attributed to strong basic sites. The relative basic amounts of the catalyst estimated from the peak areas are still not regular with the varying $\mathrm{MgO}$ content. There are also more basic sites on the surface of the $\mathrm{Mg}-\mathrm{Al}$ sample with $35 \% \mathrm{MgO}$ content.

As shown in Fig. 5, the nature of acid sites was detected by IR spectroscopy of adsorbed pyridine. For samples with $15 \sim 40 \% \mathrm{MgO}$ content, two main bands detected at $1590 \mathrm{~cm}^{-1}$ and $1450 \mathrm{~cm}^{-1}$ are attributed to $\mathrm{H}$-bonded pyridine and pyridine adsorbed on the Lewis acid sites, respectively. More interesting, adsorption strength of pyridine on catalyst surfaces slowly weakened as the $\mathrm{MgO}$ content increased so

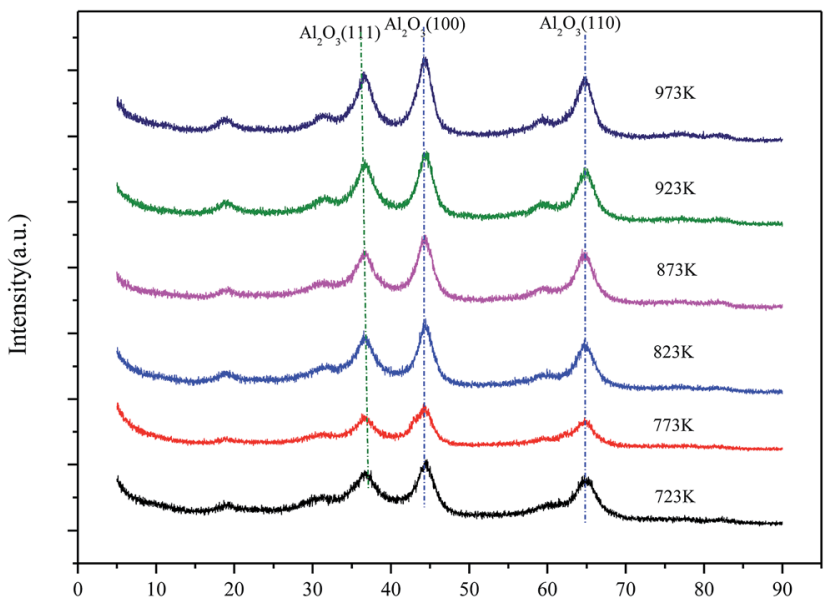

Fig. 6 XRD patterns of $35 \% \mathrm{Mg}-\mathrm{Al}$ catalysts with different calcination temperatures. that Lewis acid sites could not be detected when the $\mathrm{MgO}$ content was $45 \%$.

Based on the following catalyst activity data, $\mathrm{Mg}-\mathrm{Al}$ catalysts with $35 \% \mathrm{MgO}$ content were optimized. Now, calcination temperatures would be a more important factor needed to consider. XRD patterns of $35 \% \mathrm{Mg}-\mathrm{Al}$ catalysts with different calcination temperatures are shown in Fig. 6. Catalysts calcined at the temperatures from $723 \mathrm{~K}$ to $973 \mathrm{~K}$ only show typical features of crystalline $\mathrm{Al}_{2} \mathrm{O}_{3}$ (111), (100) and (110). No peaks due to crystalline $\mathrm{MgO}$ or any other crystalline impurity phases are discerned. But diffraction peak becomes sharper with the calcination temperature increasing, which indicates the crystallinity has improved.

Table 2 shows the structural properties of catalysts with different calcination temperatures. Both the BET surface areas and the average pore diameters fluctuate within the scope of 165-185 $\mathrm{m}^{2} \mathrm{~g}^{-1}$ and 40-60 $\mathrm{A}$, respectively. But there are still no patterns as the calcination temperature increasing, which can be confirmed by SEM images.

SEM images of the samples with different calcination temperatures are shown in Fig. 7. All the samples, as a whole, present irregularly blocky shapes. There is no apparent agglomeration body as the calcination temperature goes up, which is agreed with BET measurement. This also illustrates that calcination temperature has little influence on the catalyst morphology at the temperature range of 723-973 K.

As shown in Fig. 8, the acid site nature of catalysts with different calcination temperatures was explored by IR spectroscopy of adsorbed pyridine. For samples (a), (b) and (c), there are two bands that can be detected at $1590 \mathrm{~cm}^{-1}$ and $1450 \mathrm{~cm}^{-1}$, which are due to $\mathrm{H}$-bonded pyridine and pyridine adsorbed on the Lewis acid sites, respectively. However, no band can be observed for the samples (d), (e) and (f). That is, calcination temperature has influence on the acid site nature and higher calcination temperature makes Lewis acid sites disappear from the surface of the catalysts.

\subsection{Catalytic test for ethanol conversion}

The selectivity and product distribution of catalysts with different $\mathrm{MgO}$ contents are shown in Fig. 9(a). The results show that the reaction products were mainly $\mathrm{BD}$, ethylene, ether, acetaldehyde, 1-butene and 1-butanol. The BD selectivity increases first, and then decreases with the increase of $\mathrm{MgO}$ content. However, there is no linear relationship between other

Table 2 Structural properties of catalysts with different calcination temperatures

\begin{tabular}{lll}
\hline $\begin{array}{l}\text { Calcined } \\
\text { temperature (K) }\end{array}$ & $\begin{array}{l}\text { BET surface } \\
\text { area }\left(\mathrm{m}^{2} \mathrm{~g}^{-1}\right)\end{array}$ & $\begin{array}{l}\text { Average pore } \\
\text { diameter }(\AA)\end{array}$ \\
\hline 723 & 166.3 & 44 \\
773 & 185.0 & 41 \\
823 & 170.1 & 56 \\
873 & 175.9 & 48 \\
923 & 179.4 & 60 \\
973 & 169.1 & 49
\end{tabular}



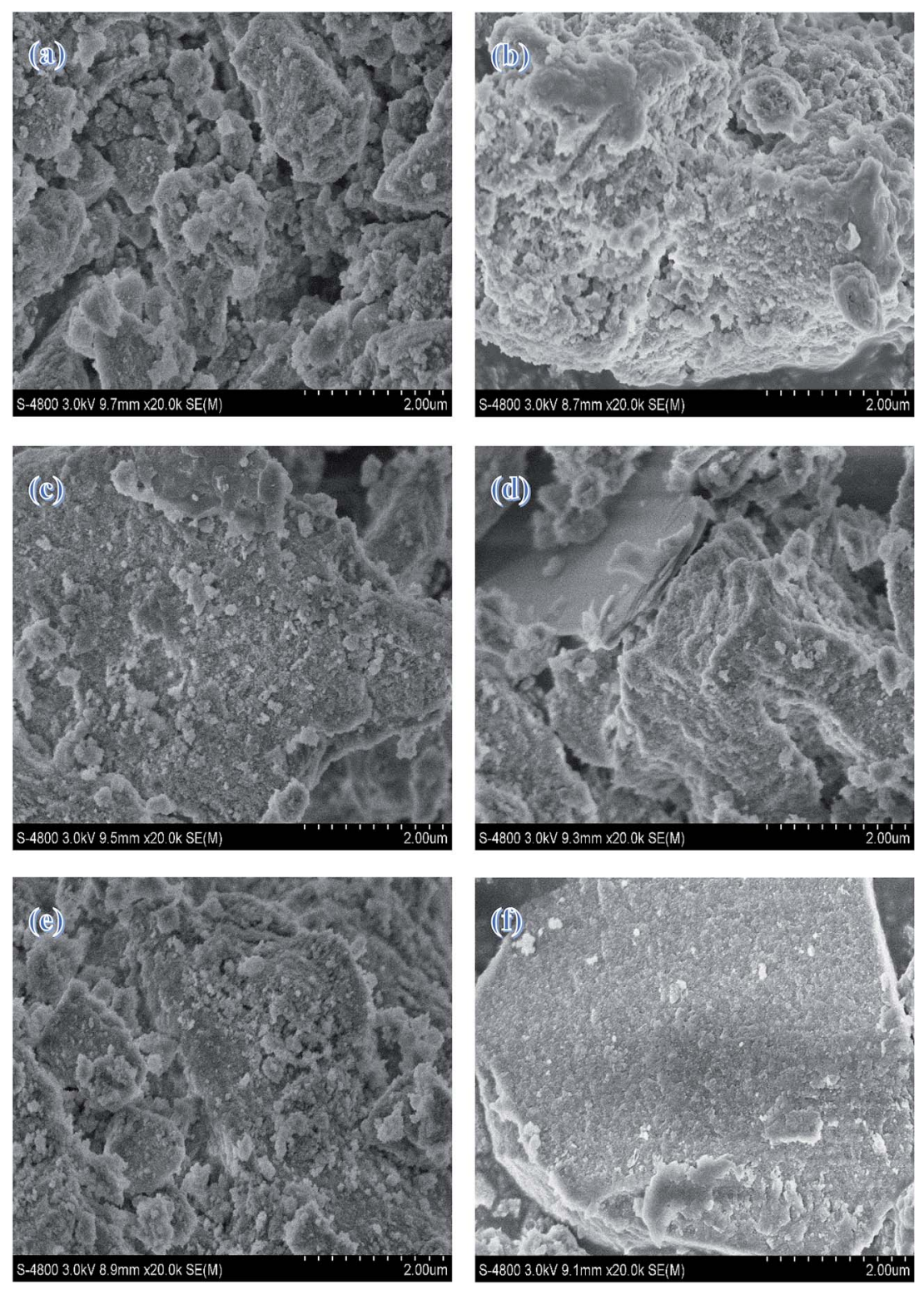

Fig. 7 SEM images of (a) Mg-Al-723 K (b) Mg-Al-773 K (c) Mg-Al-823 K (d) Mg-Al-873 K (e) Mg-Al-923 K (f) Mg-Al-973 K.

products including ethylene, ether, acetaldehyde, 1-butene as well as 1-butanol and the MgO content.

Similarly, the selectivity and product distribution of catalysts with different calcination temperatures are shown in Fig. 9(b). The selectivity of both BD and ethylene increases firstly and then decreases as calcination temperature goes up. The selectivity of diethyl ether increases with the calcination temperature. Likewise, other products such as acetaldehyde, 1-butylene and 1-butanol change irregularly as the calcination temperature varies.

The possible reasons of the above mentioned results are that the acid-basic sites suitable for BD also increase firstly and then decrease with the increase the $\mathrm{MgO}$ content and calcination temperature, but the other acid or basic sites vary irregularly with the $\mathrm{MgO}$ content and calcination temperature based on our $\mathrm{NH}_{3}$-TPD and $\mathrm{CO}_{2}$-TPD studies. On the basis of results of IR spectroscopy of adsorbed pyridine, the Lewis acid sites are appropriate for $\mathrm{BD}$ formation.

To investigate the influence of reaction conditions to bulk chemicals including reaction temperatures and the feed rate of ethanol, the following experiment was also carried out. The variation trend and specific data are summarized in Fig. 10. The suitable conditions for BD and ethylene: temperature $698 \mathrm{~K}$ and WHSV $1.4 \mathrm{~h}^{-1}$. The suitable conditions for 1-butanol: temperature $713 \mathrm{~K}$ and WHSV $1.6 \mathrm{~h}^{-1}$, and for higher reaction temperatures, the production of 1-butanol becomes much easier. The selectivity of both ethylene and 1-butanol fluctuates widely as the feed rate varies. However, the trends of products such as BD, acetaldehyde diethyl ether and 1-butylene become more moderate with the feed rate increasing. This may be due to the former is less demanding in terms of active sites while the latter has high requirement to the proper active sites. 


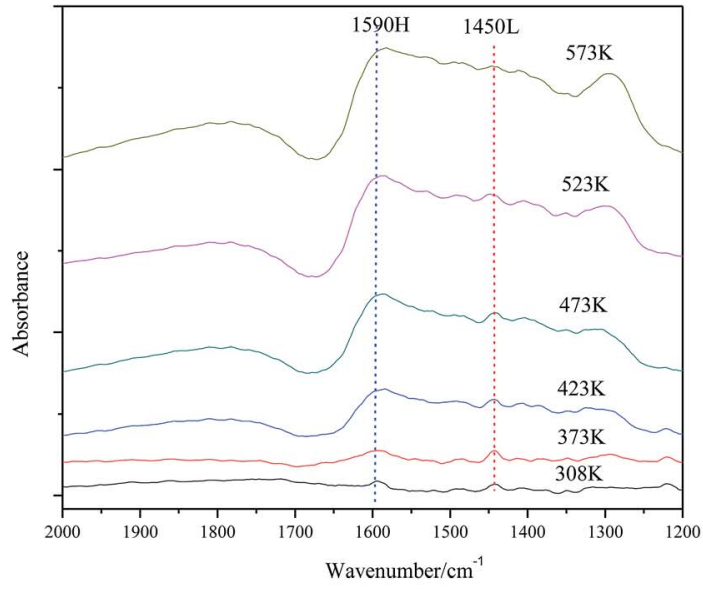

(a)

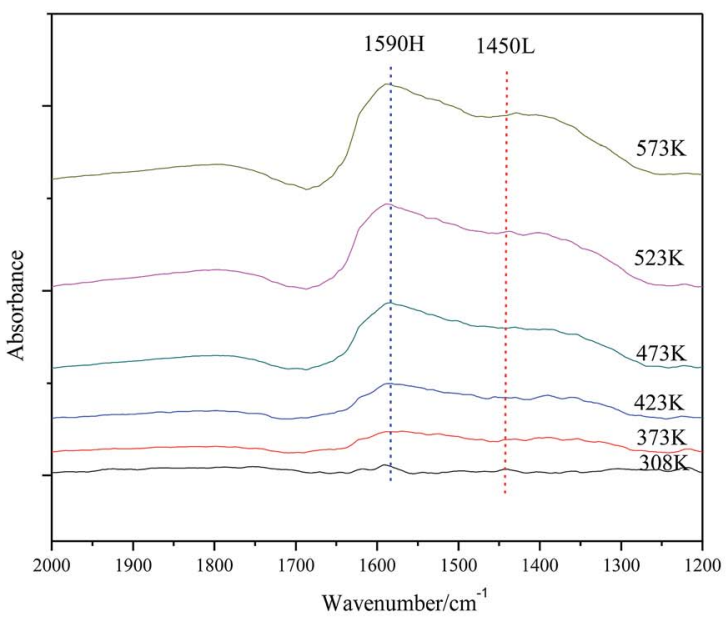

(c)

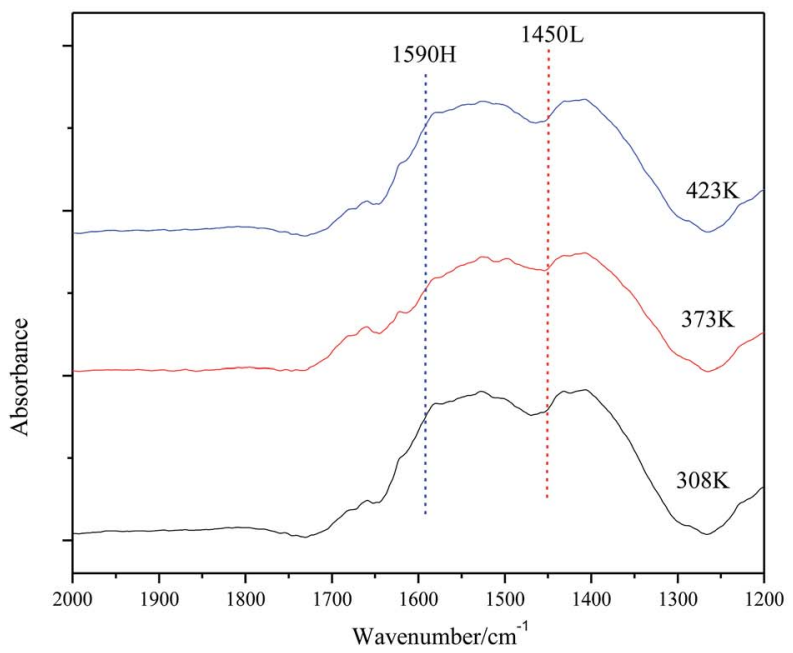

(e)

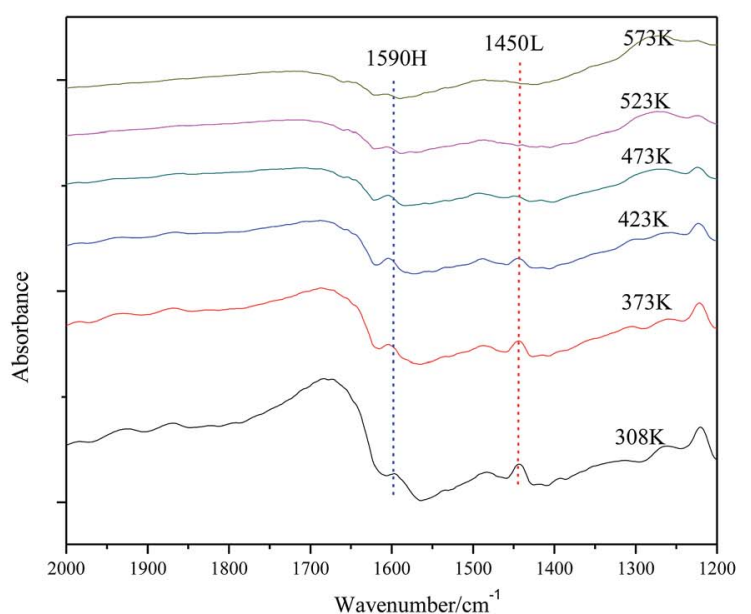

(b)

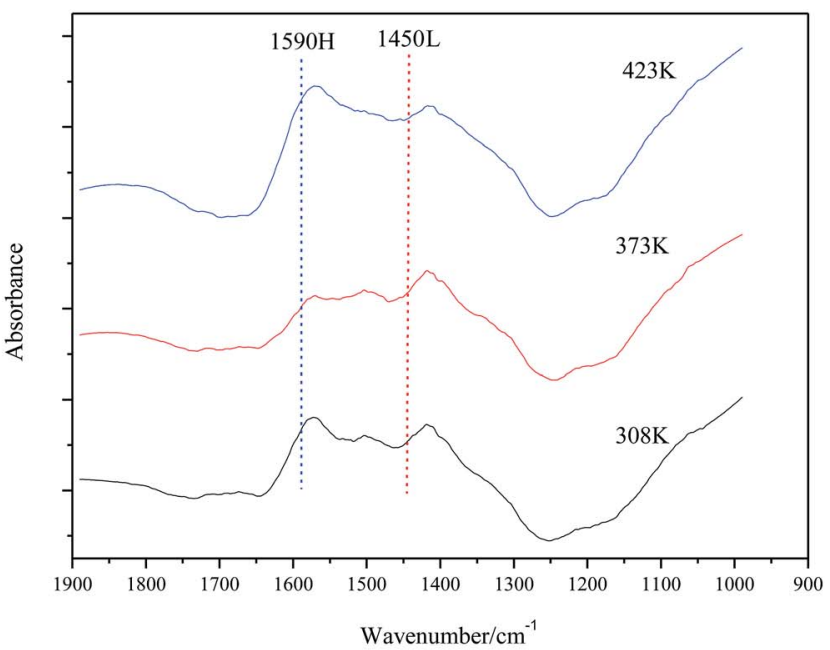

(d)

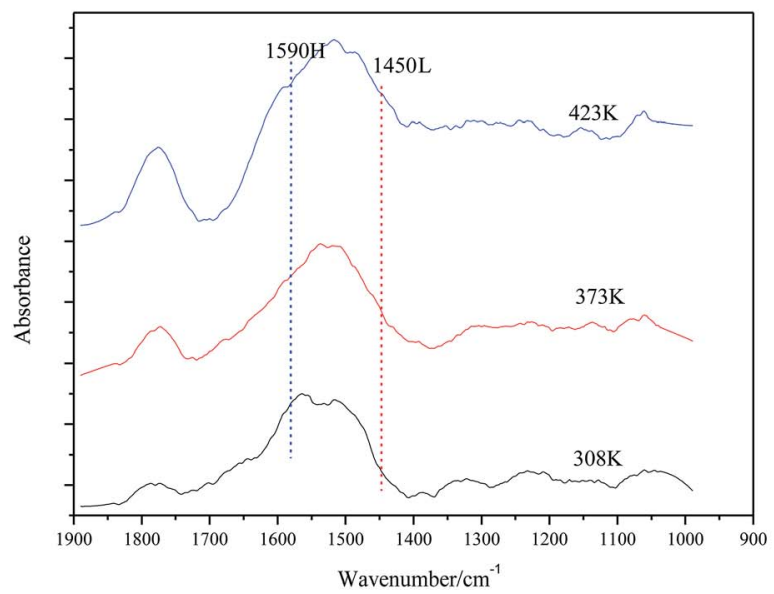

(f)

Fig. 8 FTIR spectra of (a) Mg-Al-723 K (b) Mg-Al-773 K (c) Mg-Al-823 K (d) Mg-Al-873 K (e) Mg-Al-923 K (f) Mg-Al-973 K after pyridine adsorption. 


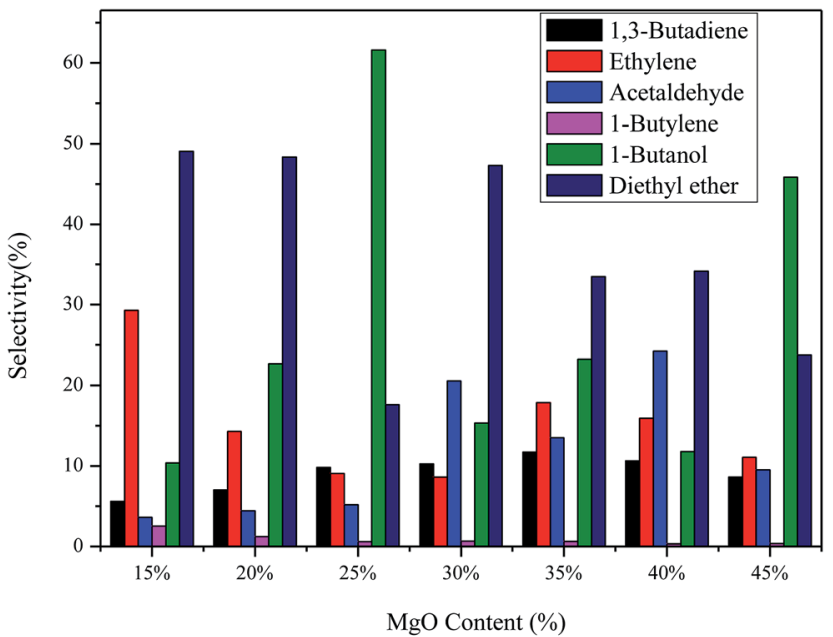

(a)

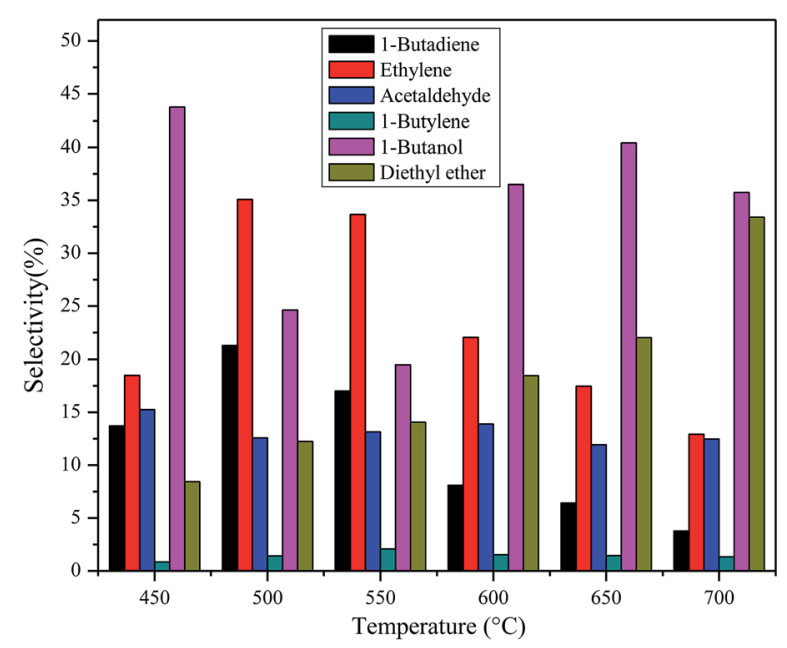

(b)

Fig. 9 The selectivity and products distribution of catalysts with different $\mathrm{MgO}$ contents (a), different calcination temperatures (b). Reaction temperature $673 \mathrm{~K}, \mathrm{WHSV} 1.8 \mathrm{~h}^{-1}$.

\section{Conclusions}

Conversion ethanol to $\mathrm{BD}$ and other bulk chemicals over $\mathrm{Mg}-\mathrm{Al}$ catalysts has been investigated. The reaction products were mainly BD, ethylene, ether, acetaldehyde, 1-butene and 1butanol.

The influence of $\mathrm{MgO}$ content has been systematic studied. The MgO content has a great impact on the catalyst structure and acid-basic properties. The BET surface areas gradually decreases as the $\mathrm{MgO}$ content increases from $15 \%$ to $45 \%$. When $\mathrm{MgO}$ content is under $40 \%, \mathrm{MgO}$ and $\mathrm{Al}_{2} \mathrm{O}_{3}$ components can be uniformly distributed in the catalyst so as to raise the activity of BD. There is no simple linear relationship between the acid as well as basic sites and MgO content. So the products selectivities based on acid, basic and acid-basic sites change irregularly.

The effect of calcination temperature on catalyst activity also has been analyzed. There are no pattern about BET surface
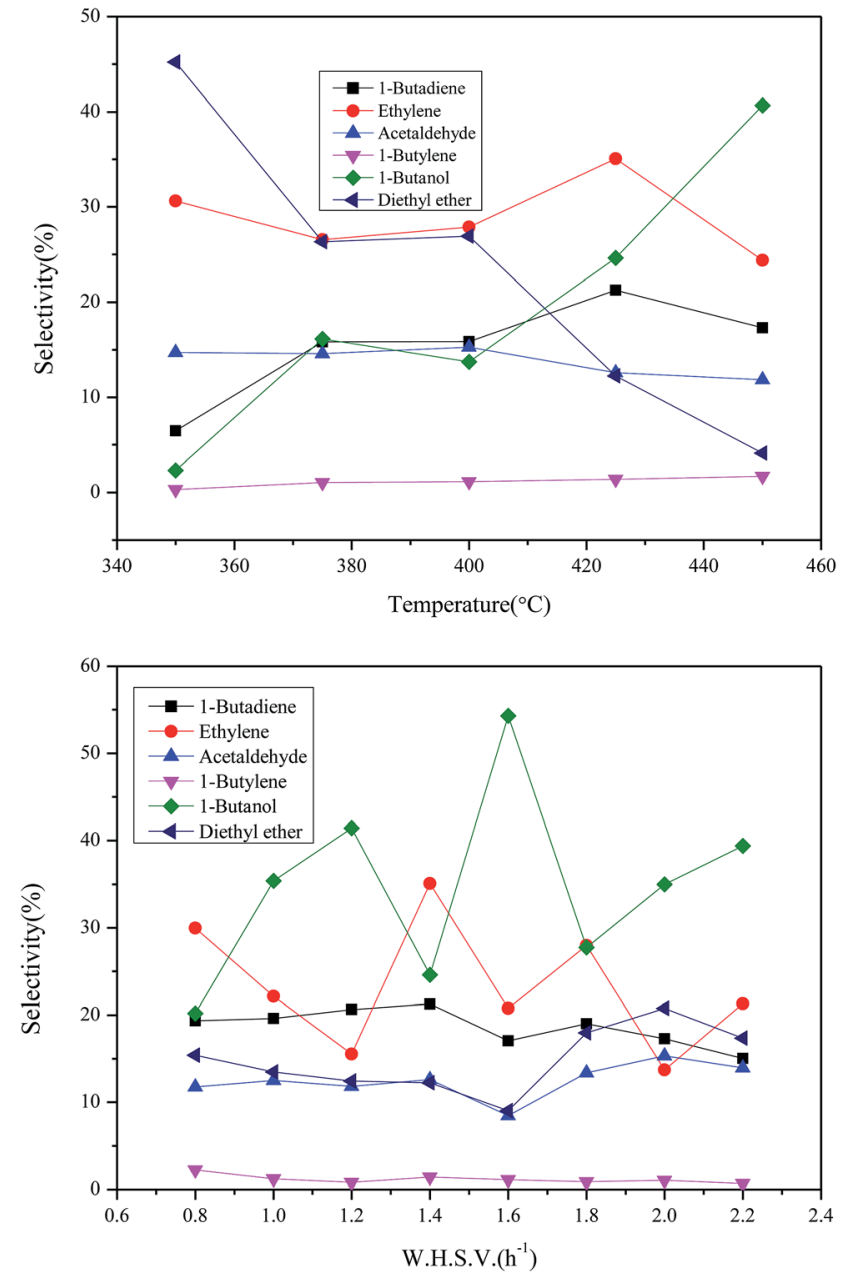

Fig. 10 The optimization of reaction conditions.

areas as the calcination temperature increasing. Both the BET surface areas and the average pore diameters fluctuate within the scope of $165-185 \mathrm{~m}^{2} \mathrm{~g}^{-1}$ and $40-60 \AA$, respectively. The acid-basic sites suitable for BD also increase firstly and then decrease with the increase the calcination temperature, but the other acid or basic sites vary irregularly with calcination temperature based on our $\mathrm{NH}_{3}$-TPD and $\mathrm{CO}_{2}$-TPD studies. On the basis of results of IR spectroscopy of adsorbed pyridine, the Lewis acid sites are appropriate for BD formation.

$35 \% \mathrm{Mg}-\mathrm{Al}$ catalysts calcined at $773 \mathrm{~K}$ show good performance for $\mathrm{BD}$ and ethylene when ethanol reacts at $698 \mathrm{~K}$ with the feed rate of $1.4 \mathrm{~h}^{-1}$. The suitable conditions for 1-butanol: temperature $713 \mathrm{~K}$ and feed rate $1.6 \mathrm{~h}^{-1}$, higher reaction temperatures, the production of 1-butanol is much easier. To further improve the product selectivity, modifiers adjusting the balance of acid-basic also need to be included in the $\mathrm{Mg}-\mathrm{Al}$ catalysts.

\section{References}

1 M. K. Jindal and M. K. Jha, RSC Adv., 2016, 6(48), 4177241780. 
2 C. Angelici, B. M. Weckhuysen and P. C. A. Bruijnincx, ChemSusChem, 2013, 6(9), 1595-1614.

3 Y. Sun and J. Y. Cheng, Biotechnol. Bioeng., 2002, 83, 1-11.

4 J. O. Alves, C. Zhuo, Y. A. Levendis and J. A. Tenório, Appl. Catal., B, 2011, 106, 433-444.

5 R. O. de Souza, L. S. Miranda and R. Luque, Green Chem., 2014, 16, 2386-2405.

6 K. D. Maher and D. C. Bressler, Biotechnol. Bioeng., 2007, 98, 2351-2368.

7 K. A. Gray, L. S. Zhao and M. Emptage, Curr. Opin. Chem. Biol., 2006, 10, 141-146.

8 P. Alvira, E. Tomas-Pejo, M. Ballesteros and M. J. Negro, Bioresour. Technol., 2010, 101(13), 4851-4861.

9 B. Hahn-Hagerdal, M. Galbe, M. F. Gorwa-Grauslund, G. Liden and G. Zacchi, Trends Biotechnol., 2006, 24, 549-556.

10 J. J. Bozell and G. R. Petersen, Green Chem., 2010, 12, 539554.

11 R. Bhatt, D. Shah, K. C. Patel and U. Trivedi, Biotechnol. Bioeng., 2008, 99, 4615-4620.

12 A. Morschbacker, J. Macromol. Sci., Polym. Rev., 2009, 49(2), 79-84.

13 R. Le Van Mao, P. Levesque, G. McLaughlin and L. H. Dao, Appl. Catal., 1987, 34, 163-179.

14 S. Ma, M. Sadakiyo, R. Luo, M. Heima, M. Yamauchi and P. J. Kenis, J. Power Sources, 2016, 301, 219-228.

15 H. B. Zasloff, US Pat. No. 4,134,926, U.S. Patent and Trademark Office, Washington, DC, 1979.
16 K. N. T. Tseng, S. Lin, J. W. Kampf and N. K. Szymczak, Chem. Commun., 2016, 52(14), 2901-2904.

17 W. C. White, Chem.-Biol. Interact., 2007, 166, 10-14.

18 W. M. Quattlebaum, W. J. Toussaint and J. T. Dunn, J. Am. Chem. Soc., 1947, 69, 593-599.

19 S. K. Bhattacharyya and N. D. Ganguly, J. Appl. Chem., 1962, 12, 105-110.

20 M. H. Zhang, M. X. Gao, J. Y. Chen and Y. Z. Yu, RSC Adv., 2015, 5(33), 25959-25966.

21 S. Kvisle, A. Aguero and R. P. A. Sneeden, Appl. Catal., 1988, 43, 117-131.

22 V. V. Ordomsky, V. L. Sushkevich and I. I. Ivanova, J. Mol. Catal. A: Chem., 2010, 333, 85-93.

23 V. L. Sushkevich, I. I. Ivanova, V. V. Ordomsky and E. Taarning, ChemSusChem, 2014, 7, 2527-2536.

24 H.-J. Chae, T.-W. Kim, Y.-K. Moon, H.-K. Kim, K.-E. Jeong, C.-U. Kim and S. Y. Jeong, Appl. Catal., B, 2014, 150, 596-604.

25 J. I. Di Cosimo, V. K. Diez, M. Xu, E. Iglesia and C. R. Apesteguia, J. Catal., 1998, 178, 99-510.

26 K. K. Rao, M. Gravelle, J. S. Valente and F. Figueras, J. Catal., 1998, 173, 115-121.

27 K. Yamaguchi, K. Ebitani, T. Yoshida and K. Kaneda, J. Am. Chem. Soc., 1999, 121(18), 4526-4527.

28 L. Hora, V. Kelbichová, O. Kikhtyanin and O. Kubička, Catal. Today, 2014, 223, 138-147.

29 M. León, E. Díaz and S. Ordóñez, Catal. Today, 2011, 164, 436-442. 